\title{
Accounting for the Temporal Fluctuation of Wind Power Production When Assessing Their Environmental Impacts with LCA: Combining Wind Power with Power-to-Gas in Denmark
}

\author{
Romain Besseau, Milien Dhorne, Paula Pérez-López, and Isabelle Blanc
}

\begin{abstract}
Worldwide wind power capacity is increasing, while the environmental footprint and economic cost of energy produced decrease. However, wind power generation is weather-dependent. At a high penetration rate, storage systems such as power-to-gas may become necessary to adjust electricity production to consumption. This research work presents the environmental life cycle performance of wind power accounting for the energy storage induced by the temporal variability of weather-dependent production and consumption. A case study in which wind power installations are combined with a power-to-gas system in Denmark to provide electricity according to the national load consumption profile was considered. Results highlight an increase, roughly by a factor 2, of the carbon footprint coming from both energy storage infrastructure and induced losses, but remain significantly, at least ten times, lower than fossil counterparts.
\end{abstract}

\section{Introduction}

Renewable energy systems (RES), promoted to limit the dependency of the energy mix to fossil fuel, and the environmental impact associated with their use are currently prospering at a global level [1].

Although RES are based on the exploitation of renewable sources, this does not mean that the renewable energy generated is impact-free. Indeed, energy and materials are necessary to build, operate, and dismantle those systems. Life cycle assessment (LCA) is an appropriate tool, often applied to assess the environmental footprint of RES [2]. LCA results published in the literature highlight that RES generally present significantly lower environmental footprint over the life cycle than fossil fuel-based alternatives [3].

R. Besseau $(\varangle) \cdot$ M. Dhorne · P. Pérez-López · I. Blanc

Mines ParisTech, PSL University, Paris, France

e-mail: romain.besseau@mines-paristech.fr 
Moreover, it is positive to note that along with the development of RES industries, the efficiency of systems and the underlying manufacturing processes have improved, leading to better environmental performance as well as economic performance with time $[4,5]$. These improvements pave the ways to a massive deployment of affordable and low environmental footprint renewable energy.

However, the electricity production of RES can be weather-dependent, as in the case of wind power, and not necessarily in adequacy with consumption. As a consequence, the massive integration of these technologies into the electricity mix requires the use of either dispatchable power plants or storage systems to be able to balance production with the consumption load profile at any time and thus maintain the grid stability [6].

With a wind power production equivalent to $45 \%$ of the annual electricity consumption in 2017, Denmark is an example of a country with high penetration of RES [7]. Thus, the balance between production and consumption strongly relies on the interconnection with Baltic countries and local combined heat and power (CHP) plants. Baltic countries are richly endowed with hydropower plants that can adjust their own production and even pump back water to store energy [8]. Denmark is also equipped with particularly flexible CHP plants [9]. Investments have been done to lower their minimum power output, provide overload ability, increase their ramping speed, and reduce the cost and time to stop and start power generation.

Existing hydropower capacities are limited, and the potential for new hydropower installations equipped with large reservoirs remains low in Europe [10]. In addition, the use of CHP plants relying on fossil fuel must be reduced as low as possible to mitigate climate change. As a consequence, new solutions for further integration of weather-dependent RES become necessary.

One of those solutions is the use of power-to-gas ( $\mathrm{P} 2 \mathrm{G})$ systems, which consist in turning electric power into synthetic gas. Electricity is used to hydrolyze water molecules and generate dihydrogen $\left(\mathrm{H}_{2}\right)$. This gas can be stored and used directly or turned into methane $\left(\mathrm{CH}_{4}\right)$ after an additional transformation called methanation. P2G, by coupling electric and gas grids, offers the possibility to store massive amount of energy over long periods of time. Thus, P2G is a storage technology able to provide long-term potentially seasonally or annually contrary to electrochemical batteries that are limited to short-term storage [11]. Once stored, the gas can be used to generate back electricity in a gas power plant or be used for mobility purposes, heat, or industrial uses. For those reasons, IEA [12] and other energy experts [11] see P2G as a determinant technology for electric systems' operation.

As RES themselves, storage technologies require materials and energy to be manufactured, operated, and dismantled and therefore involve environmental burdens. Few LCA studies have been published and most of them focus on mobility applications [13, 14]. For such applications, the P2G system is continuously used to maximize gas production and does not adapt to the fluctuations of RES production. As a consequence, $\mathrm{P} 2 \mathrm{G}$ systems considered for mobility applications present ultimate load factors of $91 \%$ approximately, corresponding to $8000 \mathrm{~h} /$ year at full load [14]. This level is much higher than what would correspond to a P2G system designed to cope with the variability of renewable energy sources. Thus, LCA 
results calculated for mobility applications cannot be directly extrapolated to assess the environmental performance of $\mathrm{P} 2 \mathrm{G}$ systems designed to balance the fluctuation of renewable energy production.

Consequently, we assessed the environmental life cycle performance of renewable energy accounting for the energy storage induced by the temporal variability of weather-dependent production and consumption. A case study in which wind power installations are combined with a power-to-gas system in Denmark to provide electricity according to the Danish load consumption profile was considered. Denmark has been chosen as wind power is highly developed with, in 2017, a production corresponding to $45 \%$ of electricity consumption [7], which is expected to increase [7], and P2G technologies already under study with a project of P2G demonstrator [15].

\section{Material and Methods}

To assess the environmental performance of a system composed of wind turbines combined with $\mathrm{P} 2 \mathrm{G}$ storage, the following elements need to be modeled and quantified:

1. The environmental impacts of wind turbines.

2. The environmental impacts of the components of a P2G system.

3. The need and use of storage.

Environmental impacts were calculated using the Python library Brightway2 [16] dedicated to LCA and using the cutoff version of ecoinvent 3.4 for background life cycle inventories.

\subsection{Environmental Impacts of the Wind Turbine}

Environmental impacts of wind turbines are assessed making use of the parametric LCA model developed and presented in detail in $[5,17]$. This parametric model uses the LCA-specific Python library Brightway2 and can be accessed online at https:// github.com/romainsacchi/LCA_WIND_DK. It enables to create tailor-made life cycle inventories of wind turbines considering their specific technological characteristics and fitting their spatiotemporal context.

Onshore and offshore wind turbines have been selected to have an environmental performance representative of the fleet. Their nominal power is $3.6 \mathrm{MW}$, and rotor diameter is $120 \mathrm{~m}$ corresponding to a power density ratio of $310 \mathrm{~W} / \mathrm{m}^{2}$. The onshore wind turbine has a $95 \mathrm{~m}$ hub height, while the offshore turbine has an $85 \mathrm{~m}$ hub height. The offshore turbines are considered to be grouped in a farm of 50 wind turbines located $5 \mathrm{~km}$ from shore, with a sea depth of $5 \mathrm{~m}$. Onshore and offshore 
wind turbines are exposed to wind resource leading to load factors of respectively $30 \%$ and $50 \%$ in coherence with measured production in Denmark [5].

\subsection{Environmental Impacts of the P2G Systems}

As for assessing wind turbines' environmental impacts, a parametric model has been developed to assess the environmental impacts of the components of a $\mathrm{P} 2 \mathrm{G}$ system.

A P2G system is composed of an electrolyzer, a methanation reactor requiring a prior system to capture $\mathrm{CO}_{2}$ in case of $\mathrm{P} 2 \mathrm{M}$ but not for $\mathrm{P} 2 \mathrm{H}$, and a power plant to generate electricity from the produced gas.

The electrolyzer is composed of cell stacks where electrolysis takes place, power electronics to feed the cells with the right current and voltage, and additional equipment such as pipes and reservoirs [18]. The cell stack is modeled by adapting the ecoinvent LCI of solid oxide fuel cell to represent the use of alkaline instead of solid oxide cell stack. To do so, lanthanum oxide is replaced by nickel and zirconium oxide by potassium. The power electronics is modeled using the existing inverter LCI originally created for photovoltaic systems. The additional equipment, which mainly consists of pipes and reservoirs, are modeled by the ecoinvent stainless steel pipe dataset. The methanation reactor is also modeled with stainless steel in accordance with the previous work from Zhang et al. [14]. Carbon dioxide is required for methanation reaction, so its extraction from the flue gas of an industrial chimney is modeled using inventories from Koornneef et al. [19]. Finally, the power plant used to burn the synthesized gas and generate electricity is modeled using the ecoinvent combined cycle gas turbine substituting the fossil gas by the synthesized gas.

The weight, lifetime, and efficiency of all the devices are based on data from industrial reports and scientific literature $[18,20]$.

\subsection{Assessment of the Need and Use of Storage}

The need and the use of storage are assessed from the comparison of energy production time series and consumption time series. The approach is represented in Fig. 1.

Firstly, wind power production time series are determined from wind speed time series and the wind turbine power curve. Wind speed data can come from on-site measurements or weather reanalysis data. MERRA-2 wind speeds have been downloaded from the online platform Renewables.ninja (https://www.renewables.ninja/) and are used in this study. Power curve gives the relationship between the wind speed the turbine is exposed to and the corresponding power output. Manufacturer power curves or modeled power curves can be used. A model able to generate a wind turbine power curve based on the nominal power, the rotor dimension and the wind turbulence intensity is used, as well as a wake loss coefficient when wind 


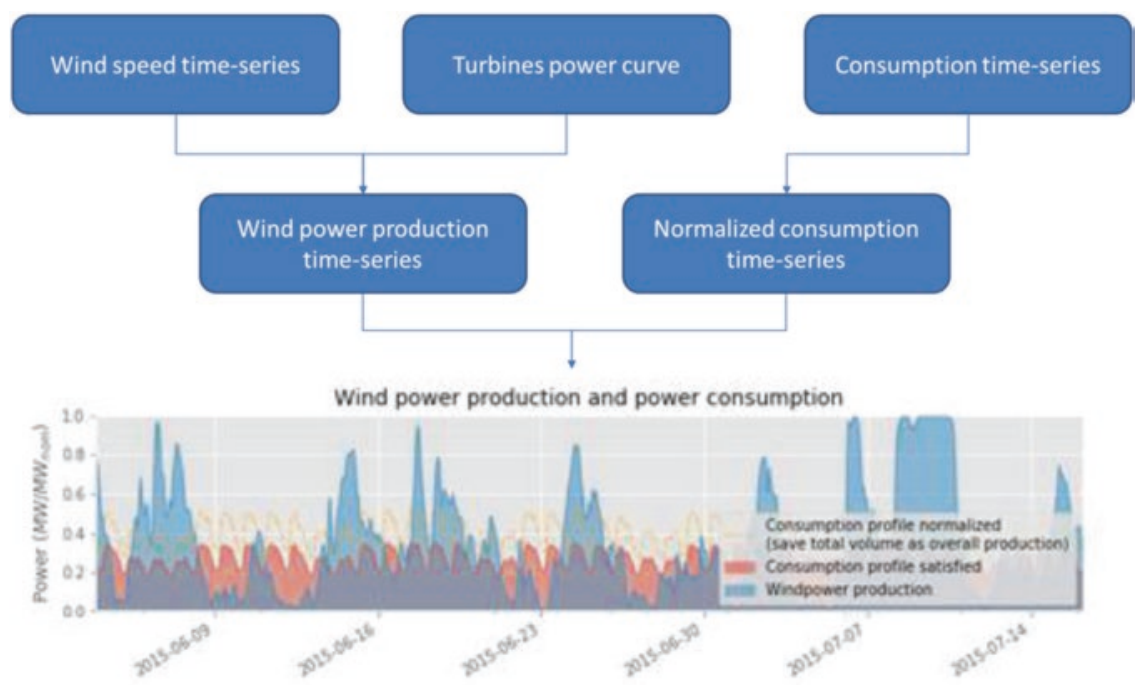

Fig. 1 Graphical representation of the approach used to assess the need and use of storage

turbines are grouped into wind farms [5]. The convolution of wind speed data with the power curve gives wind power production time series.

In a second step, this production time series is compared to the normalized Danish historical load curve. The blue curve (Fig. 1) represents the wind power production per MW installed. The orange dotted curve represents the Danish load curve with an annual consumption equivalent to the wind power production. When the production exceeds the consumption, the excess energy has to be stored, and when the production is lower, the energy difference has to be retrieved from storage. As storage induces energy losses, the amount of energy that can be retrieved from storage is lower than the amount of energy that is stored. As a consequence, a load curve corresponding to a lower annual consumption than the annual production can only be satisfied. The load curve that can be satisfied is calculated by considering the volume of energy that has to be stored and retrieved from storage and the storage efficiency.

Once the load curve is established, it is possible to get, as represented in Fig. 1:

- The wind power production in blue.

- The consumption that can be satisfied in red.

- The intersection of blue and red curves that gives the wind power production directly consumed.

- The difference between wind power production and the intersection of blue and red curves that gives the amount of energy that has to be stored when blue curve exceeds the red one, and retrieved from storage when the consumption exceeds the wind power production. 


\section{Results and Discussion}

One scenario where energy is stored with power-to-methane and one with power-tohydrogen are studied and discussed below.

\subsection{Power-to-Methane Scenario}

Figure 2A presents the carbon footprint of the energy provided by the system composed of wind turbines combined with power-to-methane storage. The carbon footprint is respectively $30 \mathrm{~g} \mathrm{CO}_{2} \mathrm{eq} / \mathrm{kWh}$ and $20 \mathrm{~g} \mathrm{CO}_{2} \mathrm{eq} / \mathrm{kWh}$ for onshore and offshore turbines. When neglecting the constraint related to weather dependency of the production, and thus the induced need for storage, the carbon footprint of energy produced is respectively 15 and $10 \mathrm{~g} \mathrm{CO}_{2} \mathrm{eq} / \mathrm{kWh}$ as illustrated by Fig. $2 \mathrm{~B}$.

In that case, considering the induced need for storage leads to an increase by a factor 2 of the carbon footprint. Figure $2 \mathrm{C}$ presents the impact per power capacity installed and highlights an increase of the carbon footprint of the system wind turbines combined with P2M storage compared to wind turbines alone. However, the difference cannot be explained only by the addition of the storage infrastructure. The second reason leading to that increase of the carbon footprint is the storage energy loss. Figure 2D shows that around half of the wind power production is

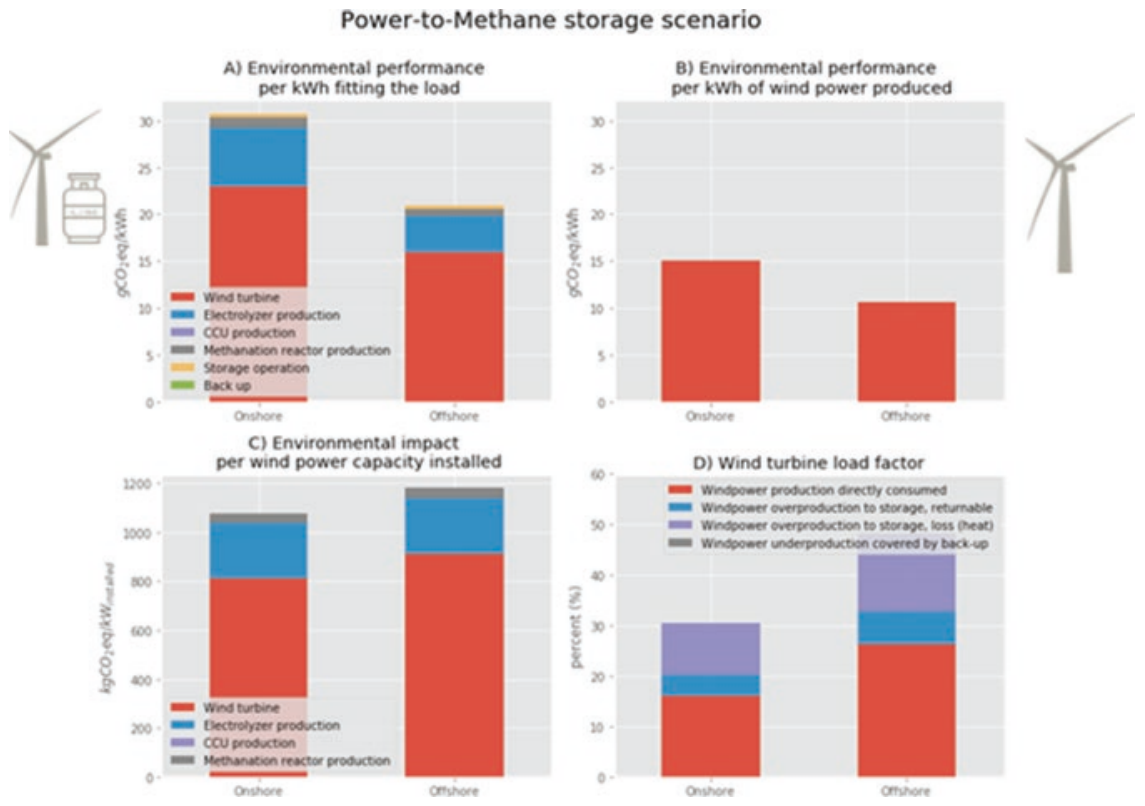

Fig. 2 Carbon footprint of wind power combined with P2M storage 
directly consumed and half goes to the storage. Considering the energy going to the storage, $70 \%$ is dissipated as heat "loss" and 30\% will be restituted as electricity. As a consequence, a significant part of the energy generated will be wasted as heat leading to an increase of the impact per $\mathrm{kWh}$ of electricity delivered by the system.

\subsection{Power-to-Hydrogen Scenario}

If $\mathrm{H}_{2}$ can be stored over long periods, $\mathrm{P} 2 \mathrm{H}$ could be used as an alternative to $\mathrm{P} 2 \mathrm{M}$ and provides as well seasonal storage. Figure 3 presents the results considering a power-to-hydrogen scenario instead of power-to-methane. The carbon footprint of wind power combined with $\mathrm{P} 2 \mathrm{H}$ is slightly higher than $25 \mathrm{~g} \mathrm{CO}_{2} \mathrm{eq} / \mathrm{kWh}$ for onshore turbines and slightly lower than $20 \mathrm{~g} \mathrm{CO}_{2} \mathrm{eq} / \mathrm{kWh}$ for offshore turbines. These values are lower than those of the power-to-methane scenario due to:

- A reduced storage infrastructure. In the absence of methanation reaction, there is no need for methanation reactors, no need for carbon capture.

- Reduced storage energy losses: the efficiency of the exothermic methanation reaction is limited to $74 \%$ [20]. Removing this step limits the decrease of the storage efficiency.

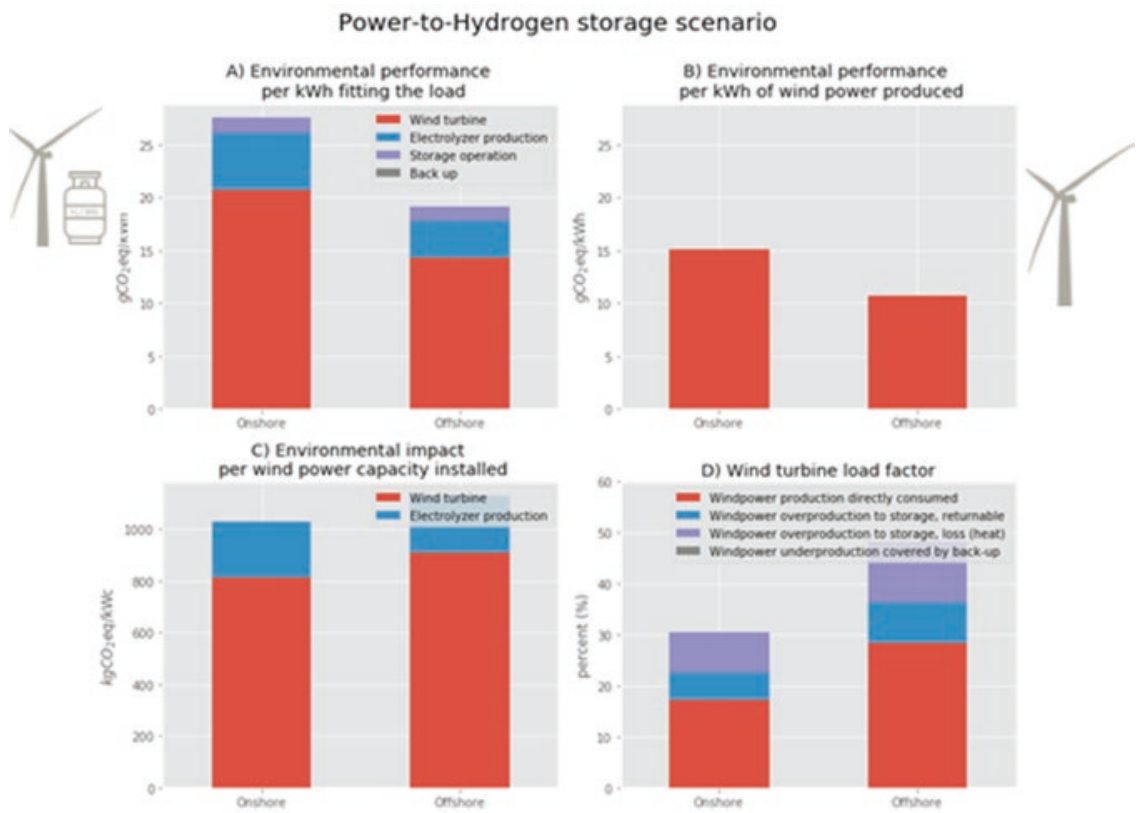

Fig. 3 Carbon footprint of wind power combined with $\mathrm{P} 2 \mathrm{H}$ storage 
However, the feasibility of this scenario is conditioned to feasibility of storing $\mathrm{H}_{2}$ over long periods. Storing massive amounts of $\mathrm{H}_{2}$ over long periods of time may be more complex due to its volatility; $\mathrm{H}_{2}$ is the smallest molecule on earth. In some countries such as the Netherlands, it is already possible to inject up to $13 \%$ of $\mathrm{H}_{2}$ into the national gas grid [21]. The feasibility of higher levels remains, to our knowledge, to be demonstrated.

Thus, $\mathrm{P} 2 \mathrm{H}$ is an option that can be considered in association with wind power to limit the carbon footprint of energy delivered. If hydrogen storage is too complex for long-term storage, a system combining $\mathrm{P} 2 \mathrm{H}$ for short-term storage with a higher efficiency and P2M to balance only long-term production variation can be contemplated.

\section{Conclusion}

An approach to account for the temporal fluctuation of wind power production when assessing their environmental impacts with LCA has been developed. This method has been applied to a case study in Denmark where wind power is combined with power-to-gas to deliver electricity according to the national load curve.

Wind power combined with P2G can deliver electricity as a dispatchable power plant with a low carbon footprint. The carbon footprint of the system "wind power + P2M" is around twice the carbon footprint of wind power system alone. This increase of the carbon footprint comes from additional storage infrastructure but also from energy losses induced by the storage. Despite being doubled, the carbon footprint remains significantly lower than the one associated with the electricity generated from fossil fuels (i.e., by at least a factor of 10). Electricity from fossil fuel typically goes from $400 \mathrm{~g} \mathrm{CO}_{2} \mathrm{eq} / \mathrm{kWh}$ for natural gas to $1000 \mathrm{~g} \mathrm{CO}_{2} \mathrm{eq} / \mathrm{kWh}$ for coal power plant [3].

The environmental footprint can potentially be reduced by limiting the power-togas storage to the hydrogen stage. Compared to $\mathrm{P} 2 \mathrm{M}, \mathrm{P} 2 \mathrm{H}$ requires less equipment for the storage, thanks to the lack of methanation and $\mathrm{CO}_{2}$ capture. In addition, it reduces the energy losses occurring during storage. However, the feasibility of this scenario is conditioned by the possibility to massively store the volatile $\mathrm{H}_{2}$ over long periods.

Whether combined with $\mathrm{P} 2 \mathrm{M}$ or $\mathrm{P} 2 \mathrm{H}$, an important share of wind power remains directly consumed. The rest is stored with significant energy losses. To improve the environmental as well as the economic performance of such a system, a key aspect is the heat waste valorization. 


\section{References}

1. IRENA. (2017). Renewable power generation costs in 2017 (p. 160). IRENA.

2. Asdrubali, F., Baldinelli, G., D’Alessandro, F., \& Scrucca, F. (2015). Life cycle assessment of electricity production from renewable energies: Review and results harmonization. Renewable and Sustainable Energy Reviews, 42, 1113-1122. https://doi.org/10.1016/j.rser.2014.10.082

3. IPCC. (2012). Renewable energy sources and climate change mitigation: Special report of the intergovernmental panel on climate change. Choice Reviews Online, 49(11), 49-6309. https:// doi.org/10.5860/CHOICE.49-6309

4. Louwen, A., van Sark, W. G. J. H. M., Faaij, A. P. C., \& Schropp, R. E. I. (2016). Re-assessment of net energy production and greenhouse gas emissions avoidance after 40 years of photovoltaics development. Nature Communications, 7, 13728. https://doi.org/10.1038/ncomms13728

5. Besseau, R. (2019). Past, present and future environmental footprint of the Danish wind turbine fleet with LCA_WIND_DK, an online interactive platform. Renewable and Sustainable Energy Reviews, 15.

6. Seck, G. S., Krakowski, V., Assoumou, E., Maïzi, N., \& Mazauric, V. (2017). Reliabilityconstrained scenarios with increasing shares of renewables for the French power sector in 2050. Energy Procedia, 142, 3041-3048. https://doi.org/10.1016/j.egypro.2017.12.442

7. Energinet. "Data: Oversigt over energisektoren," Energistyrelsen, 25-Aug-2016. [Online]. Available: https://ens.dk/service/statistik-data-noegletal-og-kort/data-oversigt-overenergisektoren. Accessed 17 Apr 2019.

8. Child, M., Bogdanov, D., \& Breyer, C. (2018). The Baltic Sea Region: Storage, grid exchange and flexible electricity generation for the transition to a $100 \%$ renewable energy system. Energy Procedia, 155, 390-402. https://doi.org/10.1016/j.egypro.2018.11.039

9. Danish Energy Agency, Energinet, EA, CNREC, and Electric Power Planning \& Engineering Institute. (2018). Thermal power plant flexibility, a publication under the clean ministerial campaign. Clean Energy Ministerial.

10. Gimeno-Gutiérrez, M., \& Lacal-Arántegui, R. (2013). Assessment of the European potential for pumped hydropower energy storage - A GIS-based assessment of pumped hydropower storage potential (p. 74). Elsevier.

11. Blanco, H., \& Faaij, A. (2018). A review at the role of storage in energy systems with a focus on power to gas and long-term storage. Renewable and Sustainable Energy Reviews, 81, 1049-1086. https://doi.org/10.1016/j.rser.2017.07.062

12. IEA. (2014). Technology roadmap energy storage (p. 64). IEA.

13. Wettstein. (2018). LCA of renewable methane for transport and mobility (p. 40). ZHAW.

14. Zhang, X., Bauer, C., Mutel, C. L., \& Volkart, K. (2017). Life cycle assessment of power-togas: Approaches, system variations and their environmental implications. Applied Energy, 190, 326-338. https://doi.org/10.1016/j.apenergy.2016.12.098

15. "P2G-BioCat." [Online]. Available: https://biocat-project.com/. Accessed 17 Jan 2020.

16. Mutel, C. (2017). Brightway: An open source framework for life cycle assessment. The Journal of Open Source Software, 2(12), 236. https://doi.org/10.21105/joss.00236

17. Sacchi, R., Besseau, R., Pérez-López, P., \& Blanc, I. (2019). Exploring technologically, temporally and geographically-sensitive life cycle inventories for wind turbines: A parameterized model for Denmark. Renewable Energy, 132, 1238-1250. https://doi.org/10.1016/j. renene.2018.09.020

18. Hydrogenics, "Electrolyzer," 2019. [Online]. Available: https://www.hydrogenics.com/wpcontent/uploads/2-1-1-industrial-brochure_english.pdf?sfvrsn=2. Accessed 10 Oct 2019.

19. Koornneef, J., van Keulen, T., Faaij, A., \& Turkenburg, W. (2008). Life cycle assessment of a pulverized coal power plant with post-combustion capture, transport and storage of $\mathrm{CO} 2$. International Journal of Greenhouse Gas Control, 2(4), 448-467. https://doi.org/10.1016/j. ijggc.2008.06.008 
20. Electrochaea, "Data-Sheet BioCat Plant," 2019. [Online]. Available: http://www.electrochaea.com/wp-content/uploads/2018/03/201803_Data-Sheet_BioCat-Plant.pdf. Accessed 10 Oct 2019.

21. Quarton, C. J., \& Samsatli, S. (2018). Power-to-gas for injection into the gas grid: What can we learn from real-life projects, economic assessments and systems modelling? Renewable and Sustainable Energy Reviews, 98, 302-316. https://doi.org/10.1016/j.rser.2018.09.007

Open Access This chapter is licensed under the terms of the Creative Commons Attribution 4.0 International License (http://creativecommons.org/licenses/by/4.0/), which permits use, sharing, adaptation, distribution and reproduction in any medium or format, as long as you give appropriate credit to the original author(s) and the source, provide a link to the Creative Commons license and indicate if changes were made.

The images or other third party material in this chapter are included in the chapter's Creative Commons license, unless indicated otherwise in a credit line to the material. If material is not included in the chapter's Creative Commons license and your intended use is not permitted by statutory regulation or exceeds the permitted use, you will need to obtain permission directly from the copyright holder. 